\title{
REORGANIZAÇÃO SIMBÓLICA DO NOVO ESPAÇO PÚBLICO: UM MODELO SEGREGADOR ORIUNDO DO PROIBICIONISMO DAS LEIS ANTIFUMO
}

\author{
Maria Teodora Farias Traldi ${ }^{1}$
}

\section{RESUMO}

Neste texto discute-se a nova forma de espaço público decorrente das restrições impostas pelas leis antifumo no Brasil. A política pública antitabagista pode ser vista como produtora de significado e valor, bem como um indicador da relação de recursos cognitivos, econômicos, organizacionais e políticos da sociedade. O Estado passa a dividir o risco com a indústria do fumo e com o próprio indivíduo como forma de preservar o equilíbrio das contas públicas. Para isso, edita leis progressivamente mais restritivas quanto ao consumo desses produtos. O proibicionismo não parece ser a melhor resposta para tal, visto que age nas consequências. Essas restrições delimitam o uso a determinados espaços, ou seja, modificando as dinâmicas sociais por técnicas de segregação. Assim, o espaço público é reorganizado simbolicamente. Acredita-se que o controle seja mais eficaz do que o combate ao fumo.

Palavras-chaves: Política pública antitabagista. Produção de significado. Simbolismo. Novo espaço público. Segregação.

\begin{abstract}
The present paper discusses the new public area due to restrictions imposed by antismoking laws in Brazil. The public policy on smoking bans can be viewed as a producer of meaning and value as well as an indicator of the relation of cognitive resources, economic, organizational and political society. The State starts to share the risks with other actors like the tobacco industry and the citizen to not compromise the balance of public accounts. In order to do this, it creates progressively more restrictive laws regarding the consumption of these products. The prohibition does not seem to be the best answer for this, because it attacks the consequences. These restrictions change the way the public area has been used, changing the social dynamics by segregation techniques. Thus, public area is symbolically reorganized. It is believed that the control is more effective than anti-smoking rules.
\end{abstract}

\footnotetext{
${ }^{1}$ Mestranda em Direito e Políticas Públicas no UniCEUB. Graduada em Administração de Empresas na UnB e em Direito no UniCEUB.E-mail: teodoratraldi@hotmail.com
} 
Keywords: Public policy on smoking bans. Production of meaning. Symbolism. New public area. Segregation.

\section{Introdução}

Homem (1863) esclarece que alertas sobre os malefícios do cigarro por parte da comunidade acadêmica de saúde no Brasil sempre existiram. No entanto, a discussão parece estar longe de se esgotar. As ciências da saúde, representada por médicos, enfermeiros e psicólogos contam com uma produtividade expressiva sobre o tema. Estes estudos são caracterizados pelas lentes destes profissionais, resultando em pesquisas acerca dos malefícios do fumo para o corpo humano. Pelas várias evidências científicas, o cigarro, sob estes enfoques, já foi condenado há muito tempo. A carência de estudos e pesquisas realizadas por profissionais de outras áreas do conhecimento, tais quais, o direito e as demais ciências sociais, acaba por não permitir uma maior oxigenação do debate, privando a inclusão de demais visões, argumentos e percepções. Essa abordagem multidisciplinar (e por que não dizer democrática) da discussão é fundamental, pois caso apenas a saúde estivesse em jogo, a fumaça e os cinzeiros não seriam mais problema. $\mathrm{O}$ diálogo entre o direito e a sociologia permite considerar o fumo como um fenômeno coletivo e prolongado, que vem causando danos cada vez maiores tanto para os fumantes quanto para os não fumantes, aqueles com o discurso em prol da liberdade individual de escolha, estes sob os argumentos de se ver com a própria saúde condenada pelas condutas dos demais.

O Estado tem seus próprios valores, nem sempre explícitos, que podem ou não coincidir com os anseios sociais. No entanto, a adesão do corpo social às propostas e metas do governo é um dos pré-requisitos para a efetividade das medidas. Assim, a política pública antitabagista pode ser vista, em princípio, como uma iniciativa que coíbe o consumo de fumígeno em ambientes coletivos. Inicialmente parece bem adequada visto os conhecidos malefícios decorrentes do consumo aos fumantes ativos e passivos. No entanto, com este marcado teor proibicionista a finalidade não tem sido propriamente alcançada, vislumbrando-se também um possível excesso no controle social formal por parte do Estado. Essas imposições unilaterais, por alterarem os hábitos da sociedade, refletem na composição do espaço público, restringindo e segregando o convívio dos grupos sociais, de modo a dificultar a vivência 
coletiva junto ao diferente. Portanto, o espaço público oriundo desse novo modelo de segregação separa grupos sociais de forma explícita transformando a qualidade do espaço público.

Para a realização deste estudo, de natureza qualitativa, optou-se pela pesquisa documental na legislação federal brasileira em vigor entre 1986 a 2010 sobre o fumo. A partir desse material, utiliza-se a técnica de análise de conteúdo para evidenciar as crenças, opiniões e significados sociais ${ }^{2}$, valendo-se de procedimentos sistemáticos e objetivos a fim de descrever o teor presente nos instrumentos normativos. Para a construção da análise acerca da mudança quanto à proibição do consumo de fumígenos em ambientes coletivos foi necessário comparar o desenvolvimento do conceito junto à Lei Antifumo do estado de São Paulo, Lei nº 13.541/2009, em função da ausência de outras fontes normativas que permitam essa análise comparativa. A partir da identificação desses elementos, relaciona-se às ponderações acerca do teor proibicionista dessas leis, servindo como subsídio para a percepção de um novo espaço público. Segundo Caldeira (2003), essa reorganização simbólica ${ }^{3}$ operacionalizada pela segregação do diferente pode transformar as concepções de público.

A importância deste estudo se dá por dois motivos. O primeiro é o fato da crescente importância do papel das políticas públicas no contexto social. Isso porque as políticas públicas podem ser vistas como uma maneira de resolver problemas e, se bem analisadas, podem evidenciar incoerências entre discurso e prática. $\mathrm{O}$ segundo consiste na percepção da mudança e transformação das concepções público-privado, na esfera de direitos e deveres no seio social e na qualidade de vida pública, em outras palavras, a reorganização simbólica propiciada pelos discursos e estratégias de proteção a partir da criação de um modelo social de segregação, ensejando um novo tipo de espaço público.

O artigo, além da introdução, é desenvolvido em mais quatro tópicos. O segundo tópico é dedicado à exposição da política pública como um paradigma, conduzindo para a análise da historicidade, das crenças e dos valores que colaboram para a construção das políticas públicas

\footnotetext{
${ }^{2}$ Geertz, seguindo os passos de Max Weber, definiu o homem como um animal amarrado a teias de significado que ele mesmo teceu, assumindo a cultura como sendo essas teias e a sua análise; portanto, não como uma ciência experimental em busca de leis, mas como uma ciência interpretativa, à procura do significado (FRANCO, 2000, p. 87).

${ }^{3}$ Sobre o poder simbólico veja BOURDIEU, P. O poder simbólico. 10. ed. Rio de Janeiro: Bertrand Brasil, 2007.
} 
em seus planos explicativo, normativo e instrumental de forma a produzir significado para a sociedade. O tópico três apresenta os problemas e a reduzida eficácia do componente proibicionista das leis antifumo. Na sequência, o quarto destina-se à identificação da reorganização simbólica que além de originar um novo espaço público a partir da segregação, acaba por repercutir nas interações das pessoas em público. Ao final, apresenta-se as considerações finais segundo as ideias expostas ao longo do texto.

\section{A política pública antitabagista como produtora de significado e valor na sociedade}

Sobre a origem das políticas públicas, ainda não há consenso entre os autores. No entanto, pode-se afirmar que essas surgiram como instrumentos para aplacar a disparidade entre os indivíduos da sociedade moderna, fato ao qual se atribuem as causas de conflitos ${ }^{4}$. O desfecho pacífico desses seria operacionalizado, teoricamente, pela administração política justa e efetiva no tocante aos bens públicos. Dessa forma, Carvalho (2000, p. 98) aponta que as políticas públicas estão relacionadas ao Estado do Bem-Estar Social e à expectativa de que este possa facilmente solucionar tais problemas. A partir da segunda metade do século $\mathrm{XX}^{5}$, com a percepção da crescente complexidade da dinâmica social, constata-se que esse modelo ideal não é capaz, por si só, de responder de forma adequada às demandas e expectativas da população.

A concepção de políticas públicas parece ser melhor explicada como uma regulação social realizada a partir de um ajuste estrutural composto pela articulação entre os mecanismos formal e informal, aquele representado pelo Estado e este, pela sociedade civil. Frigotto (2001) ressalta as dimensões pública e privada desse entendimento que prevê como âmbito de controle

\footnotetext{
${ }^{4}$ Segundo Marchesan (1993 apud LEUZINGER, 2009, p. 34), no que toca às idéias iniciais de preservação do patrimônio cultural, o advento da Revolução Francesa teria ensejado diversos movimentos em torno da questão patrimonial, culminando no surgimento de políticas públicas para a preservação e valorização dos bens representativos da nação.

5 Nesse contexto, verifica-se a "[...] tendência crescente de diversificação e complexidade do processo de organização da sociedade nas maneiras mais diversas possíveis, dos partidos políticos às entidades de classe, sindicatos, movimentos sociais, enfim, associações vinculadas a diversos interesses [...] correspondeu, de certa forma, ao movimento de expansão do Estado. [...] o processo de consolidação do Welfare State é, na verdade, também um processo de institucionalização de áreas de intervenção pública, como na saúde, habitação, saneamento, transportes, comunicação, entre outras, ocorrido no período posterior à Segunda Guerra Mundial" (PEREIRA, 1999, p. 9).
} 
o conjunto de setores da vida social, política e econômica. Há autores que enfocam as políticas públicas como integrantes ou componentes da mudança no papel estatal e não como sendo influenciadas por essa nova atuação, conferindo "visibilidade e materialidade"6 às próprias políticas e ao Estado. Para o desenvolvimento desta pesquisa ${ }^{7}$, a melhor conceituação de políticas públicas é a elaborada por Muller, a saber:

Há políticas públicas sempre que uma autoridade da política local ou nacional pretenda, por meio de um programa de ação coordenada, modificar a situação cultural e social ou econômica dos atores sociais, realizadas em geral, dentro de uma lógica setorial (MULLER apud RAPP, 2011).

O posicionamento voltado para uma análise cognitiva ultrapassa o entendimento da corrente instrumental $^{8}$ cuja percepção se reduz, basicamente, à adequação entre meios e fins. A contribuição de Muller (2000), para a formação deste conceito sob a visão cognitiva, explicita a modificação cultural oportunizada pelas políticas públicas. Desse modo, admite-se que os atores sociais atuam sobre esse quadro cognitivo, sendo importante considerar os problemas a partir do entendimento de mundo daquele grupo. Assim, o Estado é revestido de um caráter heterogêneo por ser construído com as relações e respostas dadas por esses atores à ação conflitiva. As políticas públicas resultam das interações sociais que envolvem a produção de ideias, representações e valores ${ }^{9}$ comuns àquele determinado grupo. Ao entendê-las como produções sociais de significado e valor, vislumbra-se as acumulações de recursos cognitivos, econômicos, organizacionais, culturais e políticos. Para Saravia (2006), evidencia-se a intersetorialidade como necessidade a ser observada nas etapas de elaboração das políticas públicas, fato que se

\footnotetext{
${ }^{6}$ Sobre esse enfoque veja AZEVEDO, J. M. L. A educação como política pública. Campinas: Autores Associados, 1997 e PERONI, V. M. V. Política educacional e papel do Estado no Brasil dos anos 90. São Paulo: Xamã, 2003. ${ }^{7}$ A corrente francesa de análise das políticas públicas se mostra adequada para a condução dos estudos, pois percebe que as sociedades se tornam cada vez mais complexas e setorializadas, carecendo de atuações articuladas entre instituições públicas e as diversas formas de organização presentes na sociedade civil (MULLER, 1998 apud BECERRA, 2007).

${ }^{8}$ A abordagem eminentemente instrumental tende a conceituar políticas públicas como uma coordenação seja entre os três Poderes, "seja nos níveis federativos ou no interior do Governo, considerando a interação entre organismos da sociedade civil e o Estado" (BUCCI, 2006, p. 44).

${ }^{9}$ Reis (2003) reconhece a política pública como uma reunião com elevados níveis de interligação, questões técnicas, morais e teóricas associadas a normas, valores e interesses. "A política envolve três elementos essenciais, a saber, uma teia de decisões e ações que alocam (implementam) valores; uma instância que, uma vez articulada, vai conformando o contexto no qual uma sucessão de decisões futuras serão tomadas; algo que envolve uma teia de decisões ou o desenvolvimento de ações no tempo, mais do que uma decisão única localizada no tempo"

(DAGNINO et. al., 2002).
} 
perfaz em um expressivo desafio, qual seja, a composição ${ }^{10}$ de diferentes conhecimentos e percepções em uma unidade articulada.

Através da analogia, pode-se considerar as políticas públicas como os paradigmas de Kuhn (2001). Estes são descritos como realizações científicas reconhecidas universalmente que, por algum tempo, fornecem problemas e soluções modelares para uma comunidade de praticantes de uma ciência ${ }^{11}$. Dessa forma, as políticas públicas são apreciadas como uma concepção de mundo, um modo de ver e de praticar, abarcando um conjunto de teorias, instrumentos, conceitos e métodos de investigação da realidade na qual opera. Assim, a esfera das políticas públicas vai além de meras formas de resolver problemas ou de realizar as ações governamentais podem, se bem observadas, evidenciar a incoerência entre discurso e prática. Muitas vezes, espera-se das políticas públicas a resolução de "complexos quebra-cabeças". O Estado tem seus próprios valores e estes nem sempre coincidem ou são entendidos como compatíveis com os anseios sociais ${ }^{12}$. Mesmo envolvendo o cidadão comum na cumplicidade da manutenção do sistema e /ou do grupo governante, nem sempre as políticas públicas asseguram que "a interferência do Estado na realidade social vai se dar apenas de forma a satisfazer uma carência sentida por todos os segmentos sociais, mas também para satisfazer interesses de grupos sociais diversos" (BONETI, 2007, p. 52).

A relação ${ }^{13}$ com o corpo social é fundamental para se ponderar a respeito, visto que as políticas públicas implementadas devem gozar de legitimidade a partir dos valores e crenças pactuados, de modo a conferir forte adesão ao elemento normativo imposto. O direito, neste caso, é um instrumento, serve como um suporte para a implementação das medidas. É

\footnotetext{
${ }^{10}$ Dexheimer (2004) aponta a importância dos diferentes atores na dinâmica das políticas públicas, a participação popular na formulação de políticas ambientais.

${ }^{11}$ O paradigma pode ser articulado em um processo, chamado por Kuhn (2001), de operações de limpeza, que consiste na ciência normal. Assim, os cientistas, além de saberem os objetivos antecipadamente, sabem que eles podem ser alcançados segundo determinadas regras, o que faz com que a ciência normal seja comparada à solução de complexos quebra-cabeças. Em relação às políticas públicas, servem também para interpretar e historicizar o contexto em que foram formuladas.

${ }^{12} \mathrm{O}$ Estado deve entender a comunidade como um dos atores centrais, visto que é ela quem diretamente vivencia os problemas, sendo localizada em uma posição estrutural importante, pois é a estrutura social da comunidade que dá suporte à política pública.

${ }^{13}$ Para Passeron (1995), as estruturas institucionais e sociais se entrelaçam. As políticas públicas organizam, articulam e rearticulam as interações sociais a partir de um aspecto da realidade. Dessa forma, assim como o pensamento sociológico, devem ser indexadas à história, não gozando de uma pretensão de universalidade, visto que é necessário conhecer esse "código particular" dentro de um contexto.
} 
importante reconhecer a divergência ocasionada pelo arranjo entre o conflito político e o controle organizacional, gerando tensão na sociedade visto a imposição e a regulação das condutas privadas individuais, em tese, para o bem comum público. Portanto, orquestrar a interação entre o público e o privado, pressupõe uma abordagem flexível e autônoma desta ação pública seletiva. A seletividade acaba por eleger de modo arbitrário os assuntos que são de interesse público e que devem ser objeto de intervenção estatal, refletindo a inclusão de um determinado grupo em detrimento de outro, resultando na impossibilidade de lograr uma aceitação plena ${ }^{14}$.

\section{Os problemas do teor proibicionista das leis antifumo}

A visão interdisciplinar deste estudo permite propor a discussão do tabagismo como um problema ainda atual ${ }^{15}$ da sociedade brasileira contemporânea cujo exame aparentemente se esgota nos argumentos sustentados por fumantes e não fumantes, estes preocupados em ver a própria saúde comprometida pela ação dos demais e aqueles por se entenderem na liberdade de escolha quanto ao que consumir ou não. No entanto, esses pontos de vista se mostram extremamente superficiais, não contemplando as demais variáveis e ignorando que a proibição do consumo de fumígenos em ambientes coletivos é resultado da transformação do posicionamento acerca do compartilhamento da responsabilidade e do risco entre Estado, mercado e o próprio indivíduo.

O proibicionismo demonstra ser uma medida ineficaz, independendo do produto a ser banido quer seja álcool, tabaco ou drogas. Vários setores são afetados por essas imposições morais, sociais e econômicas. Como exemplo, tem-se a Lei Seca nos Estados Unidos da América que proibiu a fabricação e o consumo de bebidas alcoólicas por mais de dez anos e

\footnotetext{
${ }^{14}$ As políticas públicas constroem os fatos a partir de um entendimento de mundo, refletindo uma negociação compartilhada de significados. Assim, não há dado puro, ele é contaminado pelas experiências do agente. Os sujeitos podem ter crenças e valores diferentes do Estado, de modo que este deve pautar a sua conduta de modo a respeitar a alteridade.

${ }^{15}$ A oportunidade da questão pode ser aferida pela discussão ainda vigente sobre as leis antifumo e pelo volume de fumantes no Brasil. Os dados mais recentes são da Pesquisa Nacional por Amostra de Domicílio (PNAD) 2008, realizada pelo Instituto Brasileiro de Geografia e Estatística (IBGE), e apontam a marca de 17,2\% de brasileiros fumantes e a quase totalidade deles (93\%) afirmou saber que essa prática pode causar doenças graves. Mesmo assim, pouco mais da metade pensava em parar, cerca de 52,1\% (IBGE, 2011).
} 
nem assim conseguiu frear o consumo de álcool. Segundo Rodrigues (2006), não obstante esse cerceamento na liberdade de escolha dos indivíduos, notou-se ainda impactos sociais colaterais, in casu, a fortificação econômica do crime organizado e o maior consumo dessa substância nos EUA. Assim, é evidente a constatação de que determinada regra ocasiona efeitos secundários muitas vezes tão danosos quanto a prática que foi restringida. No caso dessa Lei americana e nos países onde o consumo de drogas é uma conduta criminalizada, a repressão ainda acaba por aumentar a população carcerária, potencializando os conhecidos problemas acarretados pelo aprisionamento. As regulações de cunho proibitivo, de forma geral, não correspondem aos anseios da totalidade da população, muitas vezes privilegiando a imposição arbitrária de uma vontade governamental. Em outras palavras, o proibicionismo serve como instrumento de controle social estatal. A intransigência e a inflexibilidade da Lei Seca ensejaram a liberação do consumo de bebidas alcoólicas, dobrando-se a iniciativa proibicionista às pressões e influências comerciais, políticas e sociais. É importante reconhecer o desequilíbrio ocasionado pelo arranjo entre o conflito político e o controle organizacional, gerando tensões na sociedade visto a imposição e regulação das condutas privadas individuais, em tese, para o bem comum público. Mantendo as devidas proporções, na realidade brasileira o conflito experimentado pelos americanos em função da Lei Seca está sendo experienciado de forma semelhante na questão da proibição do consumo de fumígenos em ambientes coletivos.

A política pública antitabagista é marcada principalmente pelo discurso médico acerca dos malefícios à saúde. A esfera social começou a ganhar relevância quando a legislação passou a coibir o consumo de fumígenos em ambientes coletivos, mais especificamente pela Lei $n^{\circ}$ 9.294/96 considerada como a primeira lei antifumo brasileira. Cumpre salientar a substancial alteração efetuada pela promulgação da Constituição Federal de 1998 nas questões atinentes à saúde, sendo esta elevada à qualidade de direito social universal derivado do exercício da cidadania plena. Foi também ampliada e relacionada às políticas sociais e econômicas, sendo suas ações e serviços caracterizados como de relevância pública. Nem sempre a prestação de saúde pelo Estado foi feita com o objetivo primordial de melhorar o bem-estar e a qualidade de vida das pessoas. Esses outros interesses compreendiam desde a manutenção e controle da capacidade produtiva, ou seja, proteger a mão de obra e a força de trabalho até como forma de aplacar as tensões sociais. Como o atendimento, as medidas de saneamento e a medicina 
preventiva ganharam mais espaço só após 1988, as doenças que poderiam ser evitadas ou rapidamente combatidas acabavam saindo onerosas aos cofres públicos. Diante disso, percebese uma mudança no agir estatal quanto à sua responsabilidade junto à população.

Ainda que o formato "Estado-Providência" diga respeito aos países industrializados europeus, a crise experimentada por este é similar ao desequilíbrio experimentado quando os recursos para a medicina curativa começavam a ameaçar o sistema previdenciário brasileiro. Assim, o desequilíbrio financeiro acarretado pelas despesas de saúde e sociais se mostra maior que a receita ou arrecadação, impelindo que se repense não apenas a política de saúde, como a relação e o papel do Estado junto à população ${ }^{16}$. A crise é apontada tanto no modelo de desenvolvimento quanto no sistema de relações sociais, uma vez que a questão da saúde não se restringe ao doente e acaba repercutindo na qualidade de vida de todos, nas contas públicas, na mão de obra disponível entre outros aspectos.

Desse modo, a ação estatal se direciona à regulamentação e ao controle de condutas que possam aumentar seus gastos em saúde, de modo a afetar a sua capacidade econômica e equilíbrio financeiro. Conforme se verifica, as políticas públicas acabam sendo usadas também no interesse direto do Estado para delimitar comportamentos indesejáveis e para regular fins específicos, refletindo não apenas o interesse na saúde da população, como também na redução dos gastos com a saúde pública. Percebe-se uma atuação que se baseará, em um primeiro momento, na prevenção como forma de reduzir o consumo de fumígeno, refletindo na incidência de mortalidade, morbilidade, manutenção da população trabalhadora e economicamente ativa e na redução dos gastos públicos. No segundo momento, ações restritivas, como forma de exercício desse controle social formal do Estado.

A identificação do discurso proibicionista ${ }^{17}$ nas políticas públicas levanta o questionamento sobre a legitimidade do Estado para disciplinar e regrar a vida das pessoas por meio de ações estatais compulsórias. A resposta proibicionista está baseada no seu fundamento jurídico-moral, juntamente com o sanitário-social, buscando dissuadir o uso de fumígenos

\footnotetext{
${ }^{16}$ A questão do Estado-Providência é o foco do estudo de ROSANVALLON, P. A crise do Estado-Providência. Brasília: UnB, 1997.

17 “Assim, em tese, o modelo proibicionista pode ser estendido a todo tipo de consumo considerado como impróprio, inclusive o álcool e o tabaco, sendo o mais comentado exemplo a Lei Seca nos Estados Unidos, que vigorou por mais de dez anos, mas não conseguiu frear as fortes raízes do consumo social de bebidas alcoólicas" (RODRIGUES, 2006, p. 46).
} 
através da coação e da ameaça de punição representada pela aplicação de multa, tendo como resultado esperado a erradicação do consumo.

Ainda que, em princípio, pareçam bem intencionadas, essas políticas públicas antitabagistas não deixam de ser um disciplinamento e uma restrição à liberdade da prática de atos individuais no ambiente público. Ademais, essas medidas são uma comunicação entre o Estado e a população, explicitando a correlação de forças presentes na sociedade, bem como o grau de controle daquele sobre o próprio aparato estatal e sobre a sociedade, entre outros sentidos de caráter simbólico. Portanto, quando o comportamento do indivíduo torna-se objeto da intervenção do Estado, por meio do aparato legislativo, experimenta-se um controle social de modo a disciplinar o espaço público assemelhando-se aos assuntos criminais. Apesar disso, as políticas públicas antitabagistas não estão propriamente na esfera criminal, pois a violação não constitui crime e nem enseja uma pena. Ainda assim, a lógica do discurso proibicionista não invalida a utilização dos conhecimentos e das discussões elaboradas no âmbito penal. Karam (2006) acredita que as ideias proibicionistas podem ser consideradas como um posicionamento ideológico, de fundo moral, que se refletem em políticas públicas voltadas para a regulação de fenômenos, comportamentos ou produtos vistos como negativos, por meio de proibições em lei. A tendência da expansão do poder punitivo e repressivo estatal pode ocasionar uma mitigação de direitos fundamentais, trazendo riscos e danos para o Estado Democrático de Direito.

A proibição é vista como uma decisão política, consistindo em uma manifestação de poder do Estado. Esta deve ser destinada para situações extremas e urgentes sob pena de aparentemente solucionar um problema e desencadear outro. Conforme observa Medellín Torres:

Un nuevo frente de tensiones y conflictos se abre cuando desde las políticas públicas se pueden encontrar situaciones en las que la gestión de lo social puede terminar degradando lo público, así como el propósito gubernamental de regular la intimidad de las personas termina por degradar lo privado (MEDELLÍN TORRES, 2004, p. 48).

A crítica maior à abordagem proibicionista reside no fato de que esta decisão política não almeja, como se divulga, a proteção e os interesses sociais dos indivíduos, mas a uma disciplina social que seja interessante para a manutenção e reprodução de valores e interesses dominantes em um dado contexto social. Além disso, mesmo que tal medida consiga reduzir o 
número de fumantes, haverá aqueles que persistirão, sendo assim, os objetivos apenas são atingidos parcialmente e ainda, sob um possível excesso no controle social por parte do Estado. Portanto, as proibições são mecanismos repressivos de tipo totalitário, evidenciando o caráter controlador e modelador da ação estatal na vida íntima das pessoas. Impor a abstinência total e compulsória como ideal social é um objetivo irrealizável e indesejável para um Estado Democrático de Direito, "pois pressupõe uma tutela estatal completa sobre o direito de livre escolha e sobre os estilos de vida e as práticas corporais" (CARNEIRO, 2011) dos indivíduos.

Caso a proposta proibicionista fosse menos intransigente, a redução no número de fumantes poderia apontar o sucesso da medida. Sobre esse posicionamento intransigente, tem-se a posição de Escohotado:

Lícita o ilícita, toda sustancia capaz de modificar el ánimo altera la rutina psíquica, y rutina psíquica se confunde a menudo con cordura; vemos así que el abstemio acude puntualmente al psiquiatra para recibir camisas de fuerzas químicas - los decentes neurolépticos-, y la sobria dama a recibir como ansiolíticos unos toscos simulacros del opio. Sin embargo, no conozco catadores de vino que sean alcohólicos, ni gastrónomos que devoren hasta la indigestión. Lo común a ambos es convertir en arte propio una simple costumbre de otros (ESCOHOTADO, 2002, p. 1368).

No entanto, o intuito da proposta de proibição de fumígenos em ambientes coletivos mira o absoluto, permitindo ressalvas para poucos locais, concluindo-se que a proposta é com vistas a erradicar completamente o fumo. Ademais, argumenta-se que o discurso proibicionista oculta fatos, evidenciando argumentos panfletários para endossar e ratificar o posicionamento e exercício dos poderes estatais. Consiste em uma seleção artificial de cunho político para o objeto da proibição, de modo a punir o desviante, em outras palavras, o diferente.

O elemento punitivo das leis antifumo fundamenta o caráter proibicionista como a única opção para se lidar com os malefícios do consumo de fumígenos. De pronto, parece uma escolha fácil na teoria, mas difícil na prática visto que impele as pessoas a mudarem seus hábitos, gostos e escolhas e a deixar de consumir determinadas substâncias, apenas pelo fato destas serem repudiadas por "atitudes sociais que determinam quais drogas são admissíveis e atribuem qualidades éticas aos produtos químicos" (ESCOHOTADO, 1996) fabricados em laboratórios farmacêuticos. Percebe-se as influências do pensamento norteador do direito penal 
simbólico nas justificativas da proibição. Nesse sentido, a origem do modelo proibicionista repousa:

[...] sobre o fundamento moral diretamente trazido da moral protestante do século XIX, que vê na abstinência um ideal de virtude, não sendo à toa que os principais sistemas proibicionistas tenham se inspirado no catecismo das igrejas anglicanas. Como bem analisa Caballero, a "tese de abstinência" idealiza a figura de um cidadão "modelo": religioso, abstêmio, sem vícios e que vive tranqüilamente em sociedade. Contudo é de difícil realização prática, pelo dado antropológico de que as pessoas sempre consumiram algum tipo de droga. Por mais que se considerem certas virtudes sociais de comportamentos socialmente regrados e conformistas, não há como se impor um modelo ideal a toda uma sociedade (RODRIGUES, 2006, p. 47).

Esse caráter autoritário repercute na não aceitação do diferente ou de modos de vida alternativos, bem como outros hábitos, práticas e culturas ao padronizar determinados comportamentos em contextos e dinâmicas complexas e diversificadas. Quando se impõe uma forma ou modelo preestabelecido, menosprezando e segregando a diversidade, sobrepõem-se automaticamente os conteúdos e decisões de um grupo com poder dominante. Para se conhecer o mundo em que se vive, precisa-se não apenas do acesso às ações humanas e suas consequências, mas do encontro com o diferente. $\mathrm{O}$ encontro com a alteridade permite analisar elementos de figurações mais amplos, verificando a dependência mútua entre os atores sociais. Essa rede interdependente requer a capacidade de conduzir a esfera individual com a companhia dos demais. No entanto, Bauman e May (2010) salientam que o fato de dar sentido às ações dos outros a partir das próprias ações não pode funcionar como um filtro apto a afastar novas possibilidades.

\section{A reorganização simbólica do novo espaço público e a política pública antitabagista}

A construção do plano explicativo teórico-referencial da política pública antitabagista brasileira entre os anos de 1986 a 2010, limitada à análise da legislação federal vigente sobre o tema, compreende diversos instrumentos legislativos, tais quais, portarias interministeriais e do Ministério da Saúde, decretos e decretos legislativos, leis ordinárias, resoluções da Agência Nacional de Vigilância Sanitária e do Banco Central do Brasil e a própria Constituição Federal 
de 1988. Para a abordagem da questão do disciplinamento do espaço coletivo pelas políticas públicas antitabagistas, comentando-se as que interessem para o alcance desses objetivos, compara-se com a definição de espaço coletivo da Lei Antifumo do estado de São Paulo, Lei ${ }^{\circ}$ 13.541/2009. Percebe-se formas específicas na condução e disciplinamento do assunto pelo Estado. O discurso tende a ser cíclico progredindo aos poucos para o banimento do fumígeno, sob o argumento dos prejuízos à saúde e consequentemente à qualidade de vida de todos. As estratégias percebidas se direcionam para a redução tanto da oferta quanto do consumo, sendo a carga da iniciativa estatal direcionada equitativamente entre propostas preventivas ou paliativas.

As propostas preventivas se dividem em ações educativas e de conscientização da população em geral e em medidas repressivas, em outras palavras, as restrições através de advertências, multas ou privação da liberdade. Dessa forma, observou-se respostas de natureza civil, penal e administrativa para o caso de não cumprimento das determinações impostas em forma de crimes e, na maior parte, infrações sanitárias. Os argumentos mais relevantes para essas medidas estatais foram a preservação da saúde, da segurança e da qualidade de vida da coletividade. Os atores mais presentes nas normas editadas foram o mercado, representado pelas indústrias de cigarro e toda a sua cadeia produtiva, o Ministério da Saúde, a Agência Nacional de Vigilância Sanitária e os fumantes. Esse disciplinamento trouxe repercussão para diversos grupos como os trabalhadores, as crianças e os adolescentes.

A Portaria Interministerial n ${ }^{\circ} 3257$, de 22 de setembro de 1998, é oriunda dos esforços do Ministério do Trabalho e da Saúde, tendo por objetivo recomendar o desestímulo do tabagismo no ambiente laboral através da adoção de medidas restritivas ao hábito de fumar, principalmente em ambientes fechados, de ventilação reduzida ou nos que possuam sistemas de condicionamento de ar, reconhecendo a necessidade de fumantes e não fumantes.

A Lei ${ }^{\circ}$ 9.294, de 15 de julho de 1996, Lei Murad ${ }^{18}$, é conhecida como a primeira lei antifumo do Brasil, sendo regulamentada pelo Decreto ${ }^{\circ} 2.018$, de $1^{\circ}$ de outubro de 1996 . Na época, a Lei Murad consistiu em um importante avanço nas políticas públicas de controle de

\footnotetext{
${ }^{18}$ Acredita-se que o nome pelo qual a Lei no $9.294 / 96$ é conhecida, Lei Murad, seja uma homenagem ao autor do projeto que a originou, Deputado José Elias Murad. Tal observação se faz pertinente tendo em vista a coincidência de nome com a figura histórica do Sultão Murad IV do Império Otomano de 1623 a 1640. Reconhecido pela sua autoridade rígida e métodos brutais, proibiu o consumo de tabaco, café, vinho e ópio condenando à morte os infratores (ALL ABOUT TURKEY, 2011).
} 
tabaco, apesar de não tratar exclusivamente da questão. A referida lei disciplinou o uso e a propaganda de produtos fumígenos, derivados ou não do tabaco entre outras substâncias ${ }^{19}$ consideradas nocivas à saúde sujeitos às restrições e condições previstas no texto constitucional. $\mathrm{O}$ artigo $2^{\circ}$ dessa Lei, de forma inovadora passa a proibir o uso de cigarros, cigarrilhas, charutos, cachimbos ou de qualquer outro produto fumígeno, derivados ou não do tabaco, em recinto coletivo $^{20}$, público ou privado, salvo em área exclusiva a esse fim, isolada e com arejamento conveniente. Observa-se que a proteção, em princípio, repousa na conduta relacionada ao consumo de produtos cujo uso se fazem sentir no recinto e não o tabaco em si, uma vez que proíbe indistintamente produtos quer sejam derivados do tabaco ou não. O parágrafo segundo vedava o uso dos produtos supramencionados em aeronaves e veículos de transporte coletivo, autorizando apenas após transcorrida uma hora de viagem e caso houvesse, nos referidos meios de transporte parte reservada aos fumantes. Interessante observar que essa redação acabou, de certa forma, beneficiando a indústria do tabaco quando estabeleceu que fumantes e não fumantes poderiam dividir o mesmo espaço ${ }^{21}$. No entanto, tal dispositivo foi alterado pela Lei $\mathrm{n}^{\circ} 10.167 / 2000$, vedando o uso em aeronaves ${ }^{22}$ e demais veículos de transporte coletivo.

O Decreto 2.018/96 se presta a regulamentar a Lei Murad. No artigo $2^{\circ}$, a norma conceitua recinto coletivo como:

[...] local fechado destinado a permanente utilização simultânea por várias pessoas, tais como casas de espetáculos, bares, restaurantes e estabelecimentos

\footnotetext{
${ }^{19} \mathrm{O}$ artigo $1^{\circ}$ da Lei $\mathrm{n}^{\circ} 9.294$ inclui, além do tabaco e seus derivados, bebidas alcoólicas, medicamentos, terapias e defensivos agrícolas.

${ }^{20} \mathrm{O}$ parágrafo primeiro do artigo $2^{\circ}$ enumera as repartições públicas, os hospitais, postos de saúde, salas de aula, bibliotecas, recintos de trabalho coletivo e as salas de teatro e cinema como submetidas a tal restrição.

21 “[...] hoje em dia as evidências científicas mostram que áreas para fumantes, os fumódromos, não oferecem a proteção adequada contra a fumaça ambiental do tabaco (FAT)” (BIALOUS et. al, 2010).

22 Em 1998, o Ministério Público Federal ingressou com uma Ação Civil Pública com pedido de liminar contra a União para, liminarmente, determinar a proibição, em todos os voos nacionais, independentemente do tempo de duração, do uso de produtos fumígenos até que as aeronaves estivessem aptas a impedir a transposição de fumaça por todo o seu interior. O pedido da procuradoria da República no Rio Grande do Sul fundamentou a necessidade de observância das normas que proíbem o uso, salvo em área destinada exclusivamente para este fim devidamente isolada e com arejamento conveniente. Ademais, o MPF salientou que a separação física entre fumantes e não fumantes, não isolava a transposição da fumaça, frustrando, assim, a eficácia do Decreto n ${ }^{\circ}$ 2.018/96. O pedido de liminar foi concedido. BRASIL. $4^{\mathrm{a}}$ Vara Cível da Justiça Federal de Porto Alegre/RS. Ação Civil Pública com pedido de liminar ${ }^{\circ}$ 98.0025524-9, Juiz Guilherme Pinho Machado, DJE 22.10.1998. Disponível em: <http://www.guilhermepinhomachado.com.br/wp-content/uploads/2010/03/Sem-T\%C3\%ADtulo3.pdf >. Acesso em 2 jan. 2011.
} 
similares. São excluídos do conceito os locais abertos ou ao ar livre, ainda que cercados ou de qualquer forma delimitados em seus contornos.

Observa-se uma modificação que amplia o conceito de recintos de uso coletivo e da incidência das leis. A Lei Antifumo do estado de São Paulo, Lei n ${ }^{\circ} 13.541 / 2009$, entende e preceitua em seu texto tal ambiente incluindo os "[...] total ou parcialmente fechados em qualquer dos seus lados por parede, divisória, teto ou telhado, ainda que provisórios, onde haja permanência ou circulação de pessoas). A lei paulista exemplifica recintos de uso coletivo como, dentre outros, ambientes laborais, de estudo, cultura, culto religioso, lazer, esporte, entretenimento, áreas comuns de condomínios, casas de espetáculos, teatros, cinemas, bares, lanchonetes, boates, restaurantes, praças de alimentação, hotéis, pousadas, centros comerciais, bancos e similares, supermercados, açougues, padarias, farmácias e drogarias, repartições públicas, instituições de saúde, escolas, museus, bibliotecas, espaços de exposições, veículos públicos ou privados de transporte coletivo, viaturas oficiais de qualquer espécie e táxis. Conforme se verifica, o fato do local ser aberto ou fechado independe, uma vez que o âmbito de incidência da lei compreende a proibição do consumo em ambientes coletivos. A exceção se verifica para os casos taxativamente elencados no artigo $6^{\circ}$, onde a lei não será aplicada, a saber, locais de culto religioso em que o uso de produto fumígeno faça parte do ritual; às instituições de tratamento da saúde que tenham pacientes autorizados a fumar pelo médico que os assista; às vias públicas e aos espaços ao ar livre; às residências; aos estabelecimentos específica e exclusivamente destinados ao consumo no próprio local de cigarros, cigarrilhas, charutos, cachimbos ou de qualquer outro produto fumígeno, derivado ou não do tabaco, desde que essa condição esteja anunciada, de forma clara, na respectiva entrada. Ademais, os locais de culto religioso, as instituições de tratamento de saúde e os estabelecimentos destinados de forma específica e exclusiva para o consumo deverão adotar condições de isolamento, ventilação ou exaustão do ar que impeçam a contaminação dos ambientes resguardados pela lei.

Em análise, percebe-se na redação do Decreto a vedação ao consumo em recintos coletivos, garantindo o direito de fumar em áreas destinadas para tal fim, devendo ser isoladas e com arejamento conveniente. Regula ainda que essas áreas, conhecidas por fumódromos, devem apresentar condições adequadas de ventilação, seja natural ou artificial, e renovação de ar, para evitar o acúmulo de fumaça no ambiente. No que se refere a hospitais, postos de saúde, 
bibliotecas, salas de aula, teatro, cinema e nas repartições públicas federais apenas será permitido o consumo em áreas ao ar livre ou fumódromos. O Decreto deixa a juízo do titular dos gabinetes individuais de trabalho das repartições públicas federais, o uso de fumígenos. Como consequência da inobservância das prescrições da norma, o usuário estará sujeito à advertência e, nos casos de recalcitrância, à retirada do recinto pelo responsável, sem prejuízo das sanções previstas na legislação local.

A análise dessas duas normas permite afirmar os avanços experimentados no disciplinamento no uso do tabaco. Elas vão além, ao disciplinar não apenas as propagandas comerciais de produtos nocivos e suas advertências, como também o uso, o consumo e os locais onde se pode ou não fumar e as respectivas penalidades aos infratores. $\mathrm{O}$ fato de relacionar e comparar em alguns pontos leis antigas ou mais modernas, propicia a identificação de certa sistematicidade na produção normativa. Na maior parte das vezes, as legislações de 1996 relativas à temática mostram-se como um expressivo avanço em relação ao que se tinha antes, consistindo assim em um marco a se considerar no estudo da evolução e do desenvolvimento normativo do disciplinamento do fumo. Pela afinidade e progressiva restrição ao fumo, subsidiada pela correlação entre a Lei Murad, o Decreto $\mathrm{n}^{\circ} 2.018 / 96$ e a moderna Lei $\mathrm{n}^{\circ}$ 13.541/09 do estado de São Paulo, evidencia-se que, apesar do lapso de treze anos, todo o cerceamento legal, não se prestou como uma resposta aos problemas experimentados, visto a necessidade do uso contínuo e cada vez mais gravoso de normas para se buscar o atingimento dos resultados almejados.

A Portaria do Ministério da Saúde n ${ }^{\circ}$ 300, de 9 de fevereiro de 2006, institui o programa "Ministério da Saúde Livre do Tabaco" com o fim de elaborar e implementar ações educativas e curativas para conscientizar os funcionários e os visitantes da instituição em relação aos malefícios decorrentes do uso do tabaco. Essa iniciativa preconiza a importância da manutenção de condições ideais de salubridade no ambiente laboral. Conforme se observa, o âmbito de incidência é restrito ao órgão, no entanto, funciona como uma medida exemplar para os demais da Administração Pública ou da iniciativa privada, de modo que um dos principais responsáveis, o Ministério da Saúde, demonstra adesão e engajamento às propostas que condizem com a sua missão. 
Dessa forma, nota-se o disciplinamento sobre os ambientes de trabalho, trânsito seja na qualidade de passageiro de transportes coletivos, seja como condutor e a polêmica esfera do ambiente coletivo. Parece aceitável a restrição nos locais de trabalho em função da hierarquia com fins de se prestar um serviço a outrem e nos transportes coletivos visto a deficiente circulação de ar e os reduzidos espaços experimentados em aeronaves, ônibus e vans. No entanto, os mencionados "espaços coletivos" permitiriam maior flexibilidade por parte do conjunto normativo. Os espaços como área de convivência são melhores aproveitados com liberdade, de modo a permitir a expressão individual frente ao grupo, questionamentos e transformações podem ser ensejadas pelo encontro com a alteridade. Ao frequentar um ambiente homogêneo, sem estímulos e diferenças incorre-se num retrocesso e no cultivo da intolerância.

A Teoria Estrutural-Funcionalista da anomia e da criminalidade ou desvio, do seu patamar positivista anterior ao século XX, já reconhecia a importância do diferente tanto como um elemento agregador quanto questionador dos procedimentos corriqueiros. Conforme explica Baratta (2002), essa Teoria foi introduzida pelos estudos de Émile Durkheim e desenvolvida por Robert Merton. Os pilares dessa teoria é a crença de que o desvio é um fenômeno normal de toda estrutura social. Sustenta ainda que somente quando ultrapassados certos limites, o fenômeno desviante torna-se negativo para a existência e desenvolvimento da estrutura social, recaindo na condição de anomia. Dessa forma, dentro desses limites funcionais, o comportamento desviante é visto como um fator necessário e útil para a manutenção do equilíbrio e desenvolvimento sócio-cultural.

A normalidade e a funcionalidade do desvio para o grupo, consiste na provocação e questionamento da reação social e do componente moral que fundamenta e enseja essa resposta. Além disso, estabiliza e mantém vivo o sentimento coletivo que sustenta a conformidade às normas. Resulta, portanto, em uma contribuição para a transformação e a renovação social, de modo a evoluir e se repensar essas dinâmicas. Zackseski (2009) sustenta que mais cerceamento ou multas, não significa, necessariamente, que haja menos desvios. Pensar o diferente sob os limites estabelecidos entre nós e os outros, afasta qualquer empatia, ocasionando em uma redução de direitos para todos. Uma vez que "não há maior garantia de liberdade individual que a liberdade de todos" (ZACKSESKI, 2009). Ao se defender, não apenas a liberdade individual, 
como a de todos, abre-se margem à discussão das relações de poder existentes, principalmente como a "ordem social" utilizada pelo Estado para legitimar todas as suas ações, sejam elas benéficas ou não para a sociedade. Sendo assim, resistir à coercitiva regulação da vida individual põe em cheque o papel do Estado. Portanto, sob a visão do interesse público e coletivo o fumo ainda traz questões a ser melhor disciplinadas e debatidas.

\section{Considerações finais}

Disciplinar o convívio social pela imposição de regras, não é uma tarefa fácil. Ao passo que uma atitude figura como legítima, viável e o seu exercício pertencente ao direito de um grupo, outro se sente atingido com tais práticas. A questão do fumo engloba dois direitos relevantes, a saber, à vida e à liberdade. Ademais, sob o ponto de vista estatal, a questão está implicada ao equilíbrio das contas públicas de modo que a restrição ao consumo de produtos nocivos pode não apenas reduzir os gastos em saúde, como aqueles decorrentes da previdência social, bem como a manutenção da mão de obra e da qualidade de vida da população. Por isso, seria ingênuo sugerir motivações exclusivamente voltadas ao bem-estar social. A indústria do fumo atua de forma relevante na realidade socioeconômica do país, seja pelo maciço recolhimento de impostos, pela geração de empregos ou pelo fomento da atividade empresarial. No entanto, o fumo continua como um produto que acarreta uma relação de custo-benefício negativa para o País.

A partir disso, pode-se entender a questão do fumo como um verdadeiro problema social, pois causa certa perturbação do corpo social, tanto no que se refere ao atrito entre fumantes e não fumantes ocasionado pelo incômodo da contaminação de determinado ambiente pela fumaça, quanto nas medidas regulatórias cada vez mais restritivas contra a indústria do fumo, implementadas pelo Estado. Observa-se que essa perturbação tem ensejado relevantes prejuízos à saúde de fumantes ativos e passivos, na qualidade de vida pública e em uma reorganização simbólica proveniente de discursos e estratégias de proteção dos não fumantes a partir de um modelo de segregação social, resultando em um novo tipo de espaço público. Esse modelo priva o encontro com a alteridade, afastando reações importantes como o 
questionamento, a aceitação, a promoção da mudança, a ressignificação e o repensar frente ao diferente. $\mathrm{O}$ resultado disso pode levar a uma situação artificial e incoerente frente à realidade sócio-cultural experimentada ou que potencialmente poderia ser vivenciada.

A articulação entre o individual e o social, a interação entre o público e o privado, pressupõe flexibilidade ao se adotar uma ação pública seletiva. A seletividade acaba por eleger arbitrariamente os assuntos que são de interesse público e que devem ser objeto de intervenção estatal, refletindo a inclusão de um determinado grupo em detrimento de outro, resultando na impossibilidade de lograr uma aceitação plena. É importante reconhecer esse contexto mais amplo, onde coexistem substâncias nocivas proibidas cujo consumo é "semiclandestino" e outras tão nocivas quanto, mas reconhecidas como "terapêuticas" legais produzidas por laboratórios farmacêuticos. Segundo Rodrigues (2006), a diferenciação entre estas substâncias é realizada por critérios políticolegislativos.

No entanto, a mera proibição ignora o fato do fumo ser um fenômeno multidimensional integrante de intrincadas relações sociais, complexas e diversificadas. A legislação e as próprias campanhas destinadas aos fumantes devem considerar os significados, tendo em vista que apenas repor a quantidade de nicotina com artifícios não é suficiente; o hábito de fumar pode ser entendido como um sintoma e para lograr êxito na prevenção e recuperação do fumante, deve-se intervir na causa.

O desenvolvimento desta discussão caminha para a administração flexível e includente das vivências individuais dentro de um contexto coletivo, de modo a valorizar e respeitar, não apenas a diversidade, como o direito de cada um tem de escolher e praticar formas de viver de acordo com suas preferências. Por fim, a tendência do completo banimento do fumo afeta de várias maneiras a qualidade de vida pública, em outras palavras, a reorganização simbólica propiciada pelos discursos e estratégias de proteção a partir da criação de um modelo social de segregação, criam um novo tipo de espaço público. Conclui-se que as políticas públicas por serem maneiras de resolver problemas e analisar a coerência entre o discurso e a prática carecem de acuradas análises para que, articuladas às normas, operem o resultado esperado em prol do interesse público de acordo com a época, as condições sócio-políticas e culturais do contexto ao qual se destinam. 


\section{REFERÊNCIAS}

ALL ABOUT TURKEY. Sultan Murad IV. Disponível em: < http://www.allaboutturkey.com/murat4.htm>. Acesso em 15 jan. 2011.

AZEVEDO, J. M. L. A educação como política pública. Campinas: Autores Associados, 1997.

BARATTA, A. Criminologia crítica e crítica do direito penal: introdução à sociologia do direito penal. 3. ed. Rio de Janeiro: Revan, 2002.

BAUMAN, Z.; MAY, T. Aprendendo a pensar com a sociologia. Rio de Janeiro: Zahar, 2010.

BECERRA, M. H. L. El asunto de las políticas públicas. Revista Luna Azul, Manizales, mai/jun, 2007. Disponível em: <

http://lunazul.ucaldas.edu.co/index.php?option=content\&task=view\&id=330 >. Acesso em 27 nov. 2010.

BIALOUS, S. A. et. al. A resposta da indústria do tabaco à criação de espaços livres de fumo no Brasil. Revista Panamericana de Salud Pública. Washington, v. 27, n. 4, 2010. Disponível em: $<$ http://actbr.org.br/uploads/conteudo/445_paper_Brasil_SHS_final.pdf>. Acesso em 14 jan. 2011.

BONETI, L. W. Políticas públicas por dentro. 2. ed. Ijuí: Unijuí, 2007.

BOURDIEU, P. The force of law: toward sociology of the juridical field. Hastings Law Journal, Volume 38, July 1987. Disponível em: <

http://cablemodem.fibertel.com.ar/seminario/bourdieu.pdf >. Acesso em 6 jan. 2011.

BRASIL. $4^{a}$ Vara Cível da Justiça Federal de Porto Alegre/RS. Ação Civil Pública com pedido de liminar n 98.0025524-9, Juiz Guilherme Pinho Machado, DJE 22.10.1998. Disponível em: <http://www.guilhermepinhomachado.com.br/wp-content/uploads/2010/03/SemT\%C3\%ADtulo3.pdf >. Acesso em 2 jan. 2011. 
BUCCI, M. P. D. O conceito de política pública em direito. In: BUCCI, M. P. D. (Org.).

Políticas públicas: reflexões sobre o conceito jurídico. São Paulo: Saraiva, 2006.

CALDEIRA, T. P. R. Cidade de muros: crime, segregação e cidadania em São Paulo. 2. ed. São Paulo: Edusp, 2003.

CARNEIRO, H. A abstinência também é um excesso. Comunidade segura. Disponível em:< http://www.comunidadesegura.org/pt-br/MATERIA-a-abstinencia-tambem-e-um-excesso>. Acesso em 17 fev. 2011. Entrevista concedida a Marina Lemle.

CARVAlHO, A. F. Políticas públicas em turismo no Brasil. Sociedade e Cultura, Goiânia, v. 3, n. $1,2000$.

DAGNINO, R. et al. Gestão estratégica da inovação: metodologias para análise e implementação. Taubaté: Cabral Universitária, 2002. Disponível em: < http://www.oei.es/salactsi/rdagnino1.htm >. Acesso em 28 jan. 2011.

DEXHEIMER, M. A. Participação popular e política ambiental urbana. In: LEITE, J. R. M.; BELLO FILHO, N. B. (Org.). Direito ambiental contemporâneo. Barueri: Manole, 2004.

ESCOHOTADO, A. Historia de las drogas. Madrid: Alianza Editorial, 1996.

Historia general de las drogas. 5. ed. Madrid: Espasa, 2002.

FRANCO, José Luiz de Andrade. Natureza no Brasil: idéias, políticas e fronteiras. In: SILVA, Luiz Sérgio Duarte da. Relações da cidade-campo. Goiânia: UFG, 2000.

FRIGOTTO, G. Reformas educativas e o retrocesso democrático no Brasil nos anos 90. In: LINHARES, C. (Org.). Os professores e a reinvenção da escola. São Paulo: Cortez Editora, 2001.

HOMEM, J. V. T. O abuso do tabaco como causa de angina do peito. Gazeta Médica do Rio de Janeiro, Rio de Janeiro, n. 2, p. 15, 1863. 
INSTITUTO BRASILEIRO DE GEOGRAFIA E ESTATÍSTICA. PNAD 2008 Tabagismo.

Disponível em: <

http://www.ibge.gov.br/home/presidencia/noticias/noticia_visualiza.php?id_noticia=1505\&id_p agina=1>. Acesso em 2 fev. 2011.

KARAM, M. L. A Lei n ${ }^{\circ}$ 11.343/06 e os repetidos danos do proibicionismo. Boletim

IBCCRIM, São Paulo: Instituto Brasileiro de Ciências Criminais, v. 14, n. 167, 2006.

KUHN, T. S. A estrutura das revoluções científicas. 6. ed. São Paulo: Perspectiva, 2001.

LEUZINGER, M. D. Natureza e cultura: unidades de conservação de proteção integral e populações tradicionais residentes. Curitiba: Letra da Lei, 2009.

MEDELLÍN TORRES, P. La política de las políticas públicas: propuesta teórica y metodológica para el estúdio de las políticas públicas em países de frágil institucionalidad. Série Políticas Sociales, Santiago de Chile, n. 93, CEPAL, 2004.

MULLER, P. L' analyse cognitive des politiques publiques: vers une sociologie politique de l'action publique. In: Revue française de science politique, 50e année, n. 2, 2000.

PASSERON, J. C. O raciocínio sociológico: o espaço não-popperiano do raciocínio natural. Petrópolis: Vozes, 1995.

PEREIRA, C. A. S. Políticas públicas no setor de turismo. Turismo em Análise, São Paulo, v. 10, n. 2, 1999.

PERONI, V. M. V. Política educacional e papel do Estado no Brasil dos anos 90. São Paulo: Xamã, 2003.

RAPP, M. N. E. Política pública, informação e cultura. Disponível em: <http://www.rpbahia.com.br/biblioteca/pdf/MariadelasNievesEirindeRapp.pdf>. Acesso em 4 fev. 2011. 
REIS, E. P. Reflexões leigas para a formulação de uma agenda de pesquisa em políticas públicas. Revista Brasileira de Ciências Sociais, São Paulo, v. 18, n. 51, 2003.

RODRIGUES, L. B. F. Controle penal sobre as drogas ilícitas: o impacto do proibicionismo no sistema penal e na sociedade. 2006. Tese (Doutorado em Direito) - Faculdade de Direito da Universidade de São Paulo, São Paulo, 2006.

ROSANVALLON, P. A crise do Estado-Providência. Brasília: UnB, 1997.

SARAVIA, E. Introdução à teoria da política pública. In: SARAVIA, E.; FERRAREZI, E. Políticas públicas. Coletânia. Vol. 1, ENAP, 2006.

ZACKSESKI, C. M. Los modelos de prevención de conflictos y la participación ciudadana en el Distrito Federal. Iter Criminis, Ciudad de Mexico, v. 10, 2009. 